\title{
Precipitation Effects in Mg-Zn Alloys Studied by Positron Annihilation and Hardness Testing
}

\author{
P. HrušKa*, J. ČížEk, M. VlČEK, O. Melikhova and I. ProcházKA \\ Charles University in Prague, Faculty of Mathematics and Physics \\ V Holešovičkách 2, 18000 Praha 8, Czech Republic
}

\begin{abstract}
In the present work positron annihilation spectroscopy combined with Vickers hardness testing were employed in order to investigate precipitation effects in $\mathrm{Mg}-\mathrm{Zn}$ alloys. It was found that incoherent precipitates of a metastable $\mathrm{Zn}$-rich phase formed in the samples isochronally annealed above $200{ }^{\circ} \mathrm{C}$ cause hardening of the alloy.
\end{abstract}

DOI: $10.12693 /$ APhysPolA.125.718

PACS: 78.70.Bj, 61.72.J-

\section{Introduction}

$\mathrm{Mg}-\mathrm{Zn}$ system is of particular interest in searching for biomedical alloys suitable for biodegradable implants with moderate degradation rate and good mechanical properties since zinc is one of the most abundant elements in the human body [1].

The maximal $\mathrm{Zn}$ solubility in $\mathrm{Mg}$ is $6.2 \mathrm{wt} \%$ (i.e. 2.5 at. \%) at $325{ }^{\circ} \mathrm{C}[2]$. At lower temperatures $\mathrm{Zn}$ solubility in $\mathrm{Mg}$ rapidly decreases. Hence, supersaturated solid solution can be formed by rapid cooling from elevated temperatures. Appropriate subsequent thermal treatment may lead to strengthening due to formation of finally dispersed second phase particles.

In this work positron annihilation spectroscopy (PAS) was employed for investigation of precipitation effects in binary $\mathrm{Mg}-\mathrm{Zn}$ alloy. Positron lifetime (LT) spectroscopy [3] enables to identify defects and to determine their densities. Coincidence Doppler broadening (CDB) [4] carries information about local chemical environment of defects. Development of mechanical properties was characterized by Vickers hardness (HV) testing.

\section{Experimental}

Binary $\mathrm{Mg}-6$ wt\% Zn alloy (Mg6Zn) was prepared by squeeze casting under protective gas atmosphere $\left(\mathrm{Ar}+1 \% \mathrm{SF}_{6}\right)$. Two sets of samples were investigated: (i) as-cast alloys, (ii) samples subjected to $15 \mathrm{~h}$ solution treatment at $320^{\circ} \mathrm{C}$ finished by quenching into water at a room temperature. Both samples were then isochronally annealed in steps $20^{\circ} \mathrm{C} / 20 \mathrm{~min}$.

Scanning electron microscopy (SEM) observations were performed on a FEI Phenom microscope.

The HV testing was carried out using a STRUERS Duramin 300 hardness tester. In each HV test a load of $100 \mathrm{~g}$ was applied for $10 \mathrm{~s}$.

A ${ }^{22} \mathrm{Na}_{2} \mathrm{CO}_{3}$ positron source $(1 \mathrm{MBq})$ deposited on a $2 \mu \mathrm{m}$ thick Mylar foil was used. A digital positron lifetime spectrometer [5] with excellent time resolution of

\footnotetext{
*corresponding author; e-mail: peta.hruska.l@gmail.com
}

145 ps (FWHM for ${ }^{22} \mathrm{Na}$ ) was employed for LT spectroscopy. The source contribution determined using the well annealed $\mathrm{Mg}$ reference sample consists of 2 components with lifetimes of $\approx 368 \mathrm{ps}$ and $\approx 1.5 \mathrm{~ns}$, relative intensities of $\approx 7 \%$ and $\approx 1 \%$ and representing a contribution of positrons annihilated in the ${ }^{22} \mathrm{Na}_{2} \mathrm{CO}_{3}$ spot and the covering Mylar foil, respectively. The CDB measurements were carried out using a spectrometer described in $[6]$.

\section{Results and discussion}

\subsection{As cast alloy}

Figure 1a shows a SEM micrograph of the as-cast Mg6Zn alloy in Z-contrast. Diffuse Zn-enriched bands along grain boundaries separate grain interiors which appear dark due to lower Zn concentration. Thus, in the as-cast sample $\mathrm{Zn}$ is not completely dissolved in $\mathrm{Mg}$ matrix and excess $\mathrm{Zn}$ segregates at grain boundaries.
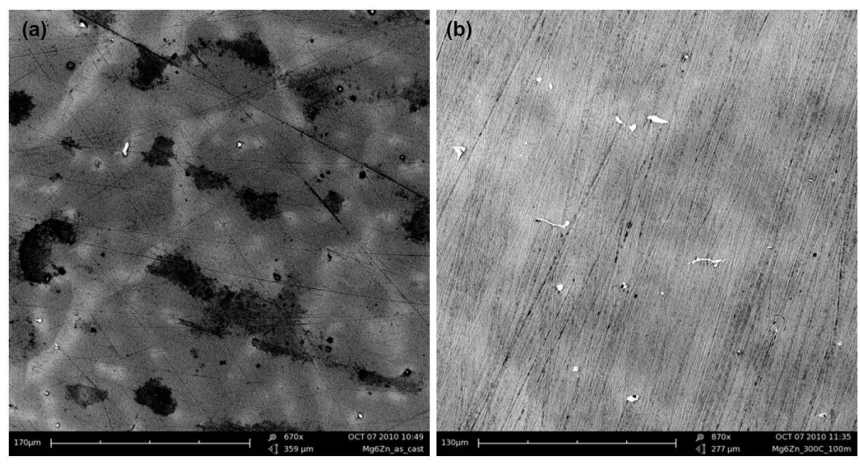

Fig. 1. SEM micrographs using backscattered electrons ( $Z$-contrast): (a) as-cast alloy, (b) sample annealed at $300{ }^{\circ} \mathrm{C}$ for $100 \mathrm{~min}$. Let us note that black spots and lines visible in the micrograph are artifacts caused by polishing of sample surface.

Temperature dependence of HV of the as-cast alloy subjected to isochronal annealing is plotted in Fig. 2a. At low annealing temperatures $\left(T<100^{\circ} \mathrm{C}\right) \mathrm{HV}$ decreases with increasing temperature most probably due to annealing of dislocations introduced into sub-surface region 
of the sample by cutting and polishing. The sample exhibits a single component LT spectrum with lifetime $\tau_{1}=222.8 \pm 0.5$ ps close to the $\mathrm{Mg}$ bulk lifetime $\tau_{\mathrm{B}}[7,8]$. This testifies that the as-cast alloy exhibits very low defect density in the bulk, dislocations induced by cutting and polishing are located in a sub-surface region.

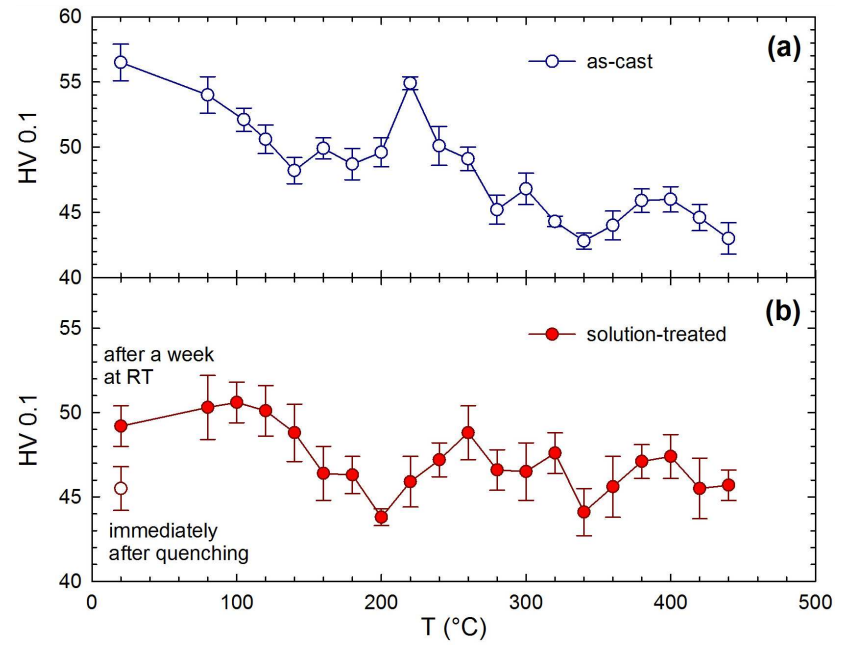

Fig. 2. Temperature dependence of HV (a) as-cast alloy, (b) solution treated alloy.

Further annealing at $T>180^{\circ} \mathrm{C}$ leads to an increase of $\mathrm{HV}$ which achieves maximum at $T=220^{\circ} \mathrm{C}$. This testifies to formation of Zn-rich second phase particles. According to the equilibrium phase diagram of $\mathrm{Mg}-\mathrm{Zn}$ system [9] formation of $\mathrm{MgZn}$ phase can be expected in the alloy studied. However formation of metastable $\mathrm{Mg}_{2} \mathrm{Zn}_{3}$ and $\mathrm{MgZn}_{2}$ phases instead of $\mathrm{MgZn}$ phase may occur [10]. Our attempt to determine the structure of the second phase by X-ray diffraction was not successful since the volume fraction of second phase is too low. Peak hardening observed at $T=220^{\circ} \mathrm{C}$ corresponds to maximum density of the second phase particles. At higher temperatures the second phase precipitates grow in size and their density becomes lower leading to a decrease of $\mathrm{HV}$. Finally, the second phase precipitates are dissolved.

The LT spectra up to $T=200^{\circ} \mathrm{C}$ are well fitted by a single component with lifetime $\tau_{1}$ falling in the range 222-223 ps which is comparable with the Mg bulk lifetime. This testifies that defect density in the alloy is very low. Above $200^{\circ} \mathrm{C}$ a second component with lifetime $\tau_{2}=256 \mathrm{ps}$ appeared in LT spectra. The relative intensity $I_{2}$ of this component is plotted in Fig. 3 as a function of annealing temperature. $I_{2}$ reaches maximum at $220^{\circ} \mathrm{C}$, i.e. at the temperature of peak hardening. The lifetime $\tau_{2}=256 \mathrm{ps}$ agrees well with the lifetime attributed to vacancy-like misfit defects at the interfaces between semicoherent or incoherent precipitates and matrix in $\mathrm{Mg}$ alloys [7]. Hence, one can conclude that the component represents a contribution of positrons trapped at vacancy-like misfit defects between Zn-rich second phase precipitates and $\mathrm{Mg}$ matrix. Growth and following

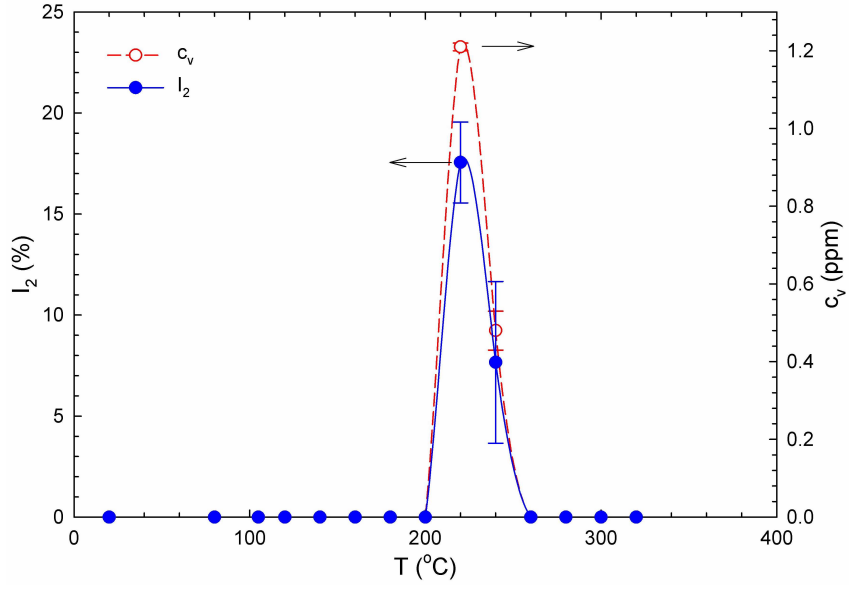

Fig. 3. Temperature dependence of intensity $I_{2}$ of positrons trapped at vacancy-like misfit defects in the as-cast alloy (full points); the concentration of vacancy-like misfit defects calculated from LT data using Eq. (1) (open points).

dissolution of the second phase precipitates above $220^{\circ} \mathrm{C}$ decreases density of misfit defects leading to a decrease of $I_{2}$, see Fig. 3. Finally at $T \geq 260{ }^{\circ} \mathrm{C} I_{2}$ becomes so small that the component cannot be resolved in the LT spectra anymore.

The concentration of misfit defects can be calculated from LT results using the two-state simple trapping model (STM) [11]:

$$
c_{\mathrm{V}}=\frac{1}{\nu_{\mathrm{V}}} \frac{I_{2}}{I_{1}}\left(\frac{1}{\tau_{\mathrm{B}}}-\frac{1}{\tau_{2}}\right) .
$$

For vacancy-like defects in metals specific positron trapping rate $\nu_{\mathrm{V}}$ usually falls into the range $10^{14}-10^{15} \mathrm{~s}^{-1}$. Here we used the lower bound $\nu_{\mathrm{V}} \approx 10^{14} \mathrm{~s}^{-1}$ according to [12]. The concentration of vacancy-like defects determined using Eq. (1) is plotted in Fig. 3 by open circles. Let us note that the quantity [12]:

$$
\tau_{\mathrm{f}}=\left(I_{1} \tau_{1}^{-1}+I_{2} \tau_{2}^{-1}\right)^{-1}
$$

was evaluated and was found to agree well with the $\mathrm{Mg}$ bulk lifetime $\tau_{\mathrm{B}}$ testifying that STM assumptions are fulfilled.

Precipitation of $\mathrm{Zn}$-rich phase at $220^{\circ} \mathrm{C}$ was detected also by CDB spectroscopy. Figure 4a shows CDB ratio curves for the as-cast and the isochronally annealed alloy up to $220^{\circ} \mathrm{C}$. The $\mathrm{CDB}$ ratio curves for pure $\mathrm{Zn}$ and $\mathrm{Mg}$ reference samples are plotted in Fig. $4 \mathrm{~b}$ for comparison. All ratio curves presented in Fig. 4a,b are related to well annealed pure Mg. Following the approach developed by Somoza et al. [13] cold rolled pure Mg sample showing saturated positron trapping at dislocations was used to estimate shape of the momentum distribution $n_{\mathrm{Mg}, \mathrm{V}}$ for positrons trapped at vacancy-like defects and annihilated by Mg electrons. One can see in Fig. 4b that the ratio curve $\varrho_{\mathrm{Mg}, \mathrm{V}}$ is enhanced at low momenta $\left(p<5 \times 10^{-3} m_{0} c\right)$ and lowered in the high momentum 


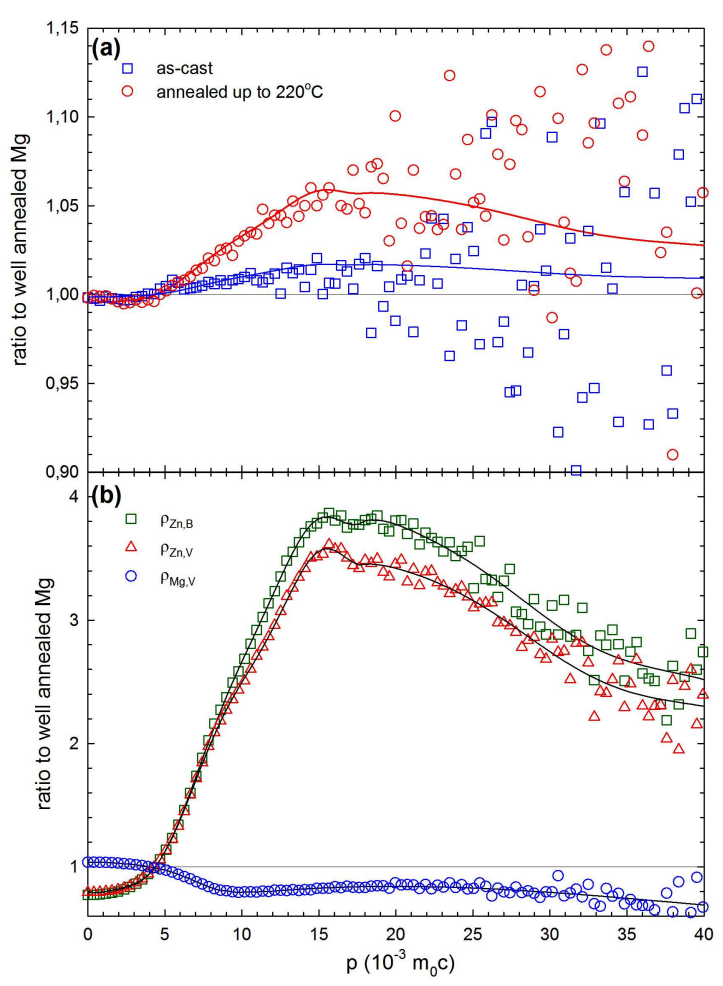

Fig. 4. (a) CDB ratio curves for the as-cast alloy and the sample isochronally annealed up to $220^{\circ} \mathrm{C}$. Solid lines are model functions calculated by Eq. (4); (b) CDB ratio curves for the well defined reference pure $\mathrm{Mg}$ and Zn samples. Solid lines are polynomial fits. All CDB ratio curves are related to well annealed $\mathrm{Mg}$.

range due to positron localization at defects. The CDB ratio curves $\varrho \mathrm{Zn}, \mathrm{B}$ and $\varrho_{\mathrm{Zn}, \mathrm{V}}$ for a well annealed $\mathrm{Zn}$ (virtually all positrons are annihilated in the free state) and heavily cold rolled $\mathrm{Zn}$ (almost all positrons are trapped at vacancy like defects) plotted in Fig. $4 \mathrm{~b}$ exhibit a broad peak with maximum located at $p \approx 16 \times 10^{-3} m_{0} c$ which comes mainly from positrons annihilated by $3 d$ Zn electrons. One can see in Fig. 4a that the contribution of positrons annihilated by $\mathrm{Zn}$ electrons is more pronounced in the alloy annealed at $220^{\circ} \mathrm{C}$ due to precipitation of Zn-rich second phase particles which introduced vacancy-like misfit defects between the precipitates and the matrix. In general, the momentum distribution for $\mathrm{Mg} 6 \mathrm{Zn}$ alloy can be expressed as a superposition of the momentum distributions measured in the reference samples

$$
\begin{aligned}
& n(p)=\left(1-F_{\mathrm{V}}\right)\left[\xi_{\mathrm{Mg}, \mathrm{B}} n_{\mathrm{Mg}, \mathrm{B}}(p)+\xi_{\mathrm{Zn}, \mathrm{B}} n_{\mathrm{Zn}, \mathrm{B}}(p)\right] \\
& \quad+F_{\mathrm{V}}\left[\xi_{\mathrm{Mg}, \mathrm{V}} n_{\mathrm{Mg}, \mathrm{V}}(p)+\xi_{\mathrm{Zn}, \mathrm{V}} n_{\mathrm{Zn}, \mathrm{V}}(p)\right] .
\end{aligned}
$$

The ratio curve related to well annealed $\mathrm{Mg}$ is obtained by dividing Eq. (3) by $n_{\mathrm{Mg}, \mathrm{B}}(p)$ :

$$
\begin{aligned}
& \varrho(p)=\left(1-F_{\mathrm{V}}\right)\left[\xi_{\mathrm{Mg}, \mathrm{B}}+\xi_{\mathrm{Zn}, \mathrm{B}} \varrho_{\mathrm{Zn}, \mathrm{B}}(p)\right] \\
& \quad+F_{\mathrm{V}}\left[\xi_{\mathrm{Mg}, \mathrm{V}} \varrho_{\mathrm{Mg}, \mathrm{V}}(p)+\xi_{\mathrm{Zn}, \mathrm{V}} \varrho_{\mathrm{Zn}, \mathrm{V}}(p)\right] .
\end{aligned}
$$

The symbol $F_{\mathrm{V}}$ in Eqs. (3) and (4) is the fraction of positrons annihilated in the trapped state at vacancy-like defects and can be calculated from LT results within STM:

$$
F_{\mathrm{V}}=\frac{I_{2}\left(\tau_{2}-\tau_{\mathrm{B}}\right)}{\tau_{2}-I_{2} \tau_{\mathrm{B}}} .
$$

The coefficients $\xi_{\mathrm{Mg}, \mathrm{B}}$ and $\xi_{\mathrm{Zn}, \mathrm{B}}$ stand for the probability that a free positron is annihilated by $\mathrm{Mg}$ or $\mathrm{Zn}$ electron, respectively. Similarly the coefficients $\xi_{\mathrm{Mg}, \mathrm{V}}$ and $\xi_{\mathrm{Zn}, \mathrm{V}}$ denote the probability that a positron trapped at a vacancy-like defect will be annihilated by $\mathrm{Mg}$ and $\mathrm{Zn}$ electron, respectively, and characterizes, thereby, chemical environment of vacancy-like defects.

Solid lines plotted in Fig. 4a show fits of ratio curves by Eq. (4) and are in a good agreement with experimental points. For the as-cast alloy $F_{\mathrm{V}}=0$ (virtually all positrons are annihilated in the free state) and $\xi_{\mathrm{Zn}, \mathrm{B}}=0.006 \pm 0.001$. This value is lower than the atomic concentration of $\mathrm{Zn}$ in Mg6Zn alloy (2.3 at.\%) which confirms that $\mathrm{Zn}$ is not completely dissolved in $\mathrm{Mg}$ matrix and excess $\mathrm{Zn}$ atoms segregate at grain boundaries as observed by SEM, see Fig. 1a. For the alloy annealed up to $220^{\circ} \mathrm{C} \xi_{\mathrm{Zn}, \mathrm{B}}=0.010 \pm 0.004$ and $\xi_{\mathrm{Zn}, \mathrm{V}}=0.50 \pm 0.05$ were obtained from fitting. Hence, annealing caused an increase of $\xi_{\mathrm{Zn}, \mathrm{B}}$ since a portion of $\mathrm{Zn}$ segregated at grain boundaries was dissolved in $\mathrm{Mg}$ matrix. Rather high value of $\xi_{\mathrm{Zn}, \mathrm{V}}$ exceeding significantly the average $\mathrm{Zn}$ concentration in the alloy testifies that vacancy-like defects are surrounded by Zn-rich environment. This supports the picture that positrons are trapped at misfit defects between $\mathrm{Zn}$-rich precipitates and $\mathrm{Mg}$ matrix.

\subsection{Solution treated alloy}

A SEM micrograph in Z-contrast of Mg6Zn alloy annealed at $300{ }^{\circ} \mathrm{C}$ for $100 \mathrm{~min}$ and quenched down to room temperature is shown in Fig. 1b. Since some portion of excess $\mathrm{Zn}$ segregated at grain boundaries dissolved in $\mathrm{Mg}$ matrix, however slightly brighter regions along grain boundaries are still visible indicating that annealing for 100 min was not long enough for a complete dissolution of $\mathrm{Zn}$ in the $\mathrm{Mg}$ matrix.

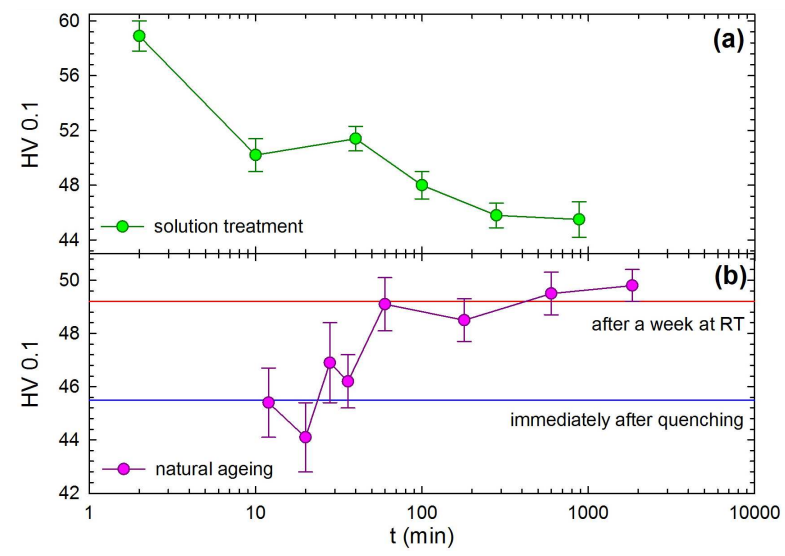

Fig. 5. (a) Development of $\mathrm{HV}$ during solution treatment of $\mathrm{Mg} 6 \mathrm{Zn}$ at $320^{\circ} \mathrm{C}$; (b) ageing of solution treated alloy at ambient temperature. The bottom line refers to $\mathrm{HV}$ of solution treated alloy immediately after quenching. The upper line refers to $\mathrm{HV}$ of solution treated alloy after a week at room temperature. 
Thus, by long-term solution treatment at $320^{\circ} \mathrm{C}$ followed by quenching the concentration of $\mathrm{Zn}$ in $\mathrm{Mg}$ matrix can be enhanced and the distribution of $\mathrm{Zn}$ can be made more uniform. Figure 5a shows development of $\mathrm{HV}$ during solution treatment at $320^{\circ} \mathrm{C}$. HV decreases and finally converges to $\mathrm{HV} \approx 46$, i.e. to a value comparable to that measured in the sample isochronally annealed up to $320^{\circ} \mathrm{C}$, see Fig. 2a. The alloy solution treated for $15 \mathrm{~h}$ was quenched to room temperature and subsequently isochronally annealed in the same regime as the as-cast alloy in order to examine the influence of solution treatment on the precipitation processes. The temperature dependence of $\mathrm{HV}$ during isochronal annealing of the solution treated alloy is plotted in Fig. $2 \mathrm{~b}$. The hardening above $200^{\circ} \mathrm{C}$ caused by precipitation of $\mathrm{Zn}$ -rich second phase particles is remarkably lower. Moreover, in the solution treated alloy $\mathrm{HV}$ firstly increases at low temperatures and reaches maximum at $100^{\circ} \mathrm{C}$, which is opposite to the behaviour of the as-cast alloy. Interestingly, the solution treated alloy measured immediately after quenching exhibits $\mathrm{HV}=46 \pm 1$, but when the sample was left at ambient temperature for one week $\mathrm{HV}$ increased to $49 \pm 1$, see Fig. 2b. This indicates that dissolved $\mathrm{Zn}$ atoms agglomerate at ambient temperature into small clusters which are obstacles for movement of dislocations and cause an increase of HV. Clustering of $\mathrm{Zn}$ atoms is easier in the solution treated sample, because the mean distance among dissolved $\mathrm{Zn}$ atoms is lower and the driving force for clustering is higher due to higher degree of supersaturation.

In order to investigate ageing of Mg6Zn alloy in detail the solution treated sample was kept at ambient temperature and development of $\mathrm{HV}$ was examined. Figure $5 \mathrm{~b}$ shows $\mathrm{HV}$ as a function of time of ageing. It is clear that $\mathrm{HV}$ increases during ageing and converges to $\mathrm{HV} \approx 50$ after ageing for $\approx 15 \mathrm{~h}$. Hence, the increase of $\mathrm{HV}$ at low temperatures observed in the solution treated sample in Fig. $2 \mathrm{~b}$ is most probably due to clustering of dissolved $\mathrm{Zn}$ atoms. The same phenomenon is responsible also for lower hardening at $T>200^{\circ} \mathrm{C}$ since due to agglomeration of $\mathrm{Zn}$ atoms the second phase particles become coarser than in the as-cast alloy.

\section{Conclusions}

Precipitation effects in Mg6Zn alloy were investigated by PAS combined with $\mathrm{HV}$ testing. It was found that Zn-rich second phase particles are formed in the tem- perature range from 200 to $260^{\circ} \mathrm{C}$ and cause noticeable hardening of the alloy. Vacancy-like misfit defects are formed at interfaces between the Zn-rich second phase particles and the $\mathrm{Mg}$ matrix. In the as-cast alloy only some portion of $\mathrm{Zn}$ is dissolved in matrix. Remaining excess $\mathrm{Zn}$ atoms are located in bands along grain boundaries. Solution treatment at $320^{\circ} \mathrm{C}$ enables to dissolve more $\mathrm{Zn}$ in the matrix. Solution treated samples exhibit ageing at ambient temperature due to clustering of dissolved Zn atoms. Agglomeration of $\mathrm{Zn}$ atoms leads to coarser second phase particles and reduces precipitation hardening in the solution treated samples.

\section{Acknowledgments}

This work was supported by the Czech Science Agency (project P108/10/0648) and by the grant SVV-2013-267303. M.V. acknowledges financial support by the Grant Agency of Charles University (project no. 566012).

\section{References}

[1] M. Staiger, A. Pietak, J. Huadmai, G. Dias, Biomaterials 27, 1728 (2006).

[2] H. Okamoto, J. Phase Equilibria Diffus. 15, 129 (1994).

[3] P. Hautojärvi, in: Positrons in Solids, Ed. P. Hautojärvi, Springer-Verlag, Berlin 1979, p. 1.

[4] P. Asoka-Kumar, M. Alatalo, V. Ghosh, A. Kruseman, B. Nielsen, K. Lynn, Phys. Rev. Lett. 77, 2097 (1996).

[5] F. Bečvář, J. Čížek, I. Procházka, J. Janotová, Nucl. Instrum. Methods Phys. Res. A 539, 372 (2005).

[6] J. Čížek, M. Vlček, I. Procházka, Nucl. Instrum. Methods Phys. Res. A 623, 982 (2010).

[7] J. Čížek, I. Procházka, B. Smola, I. Stulíková, V. Očenášek, J. Alloys Comp. 430, 92 (2007).

[8] J.M.C. Robles, E. Ogando, F. Plazaola, J. Phys., Condens. Matter 19, 176222 (2007).

[9] W. Hume-Rothery, E. Rounsefell, J. Inst. Met. 41, 119 (1929).

[10] X. Gao, J. Nie, Scr. Mater. 56, 645 (2007).

[11] R. West, in Ref. [3], p. 89.

[12] P. Hautojärvi, C. Corbel, in: Proc. Int. School of Physics "Enrico Fermi", Course CXXV, Eds. A. Dupasqier, A. Mills, IOS Press, Varenna 1995, 491.

[13] A. Somoza, M. Petkov, K. Lynn, A. Dupasquier, Phys. Rev. B 65, 094107 (2002). 